1 Denning CR, Sommers SC, Quigley HJ. Infertility in male patients with cystic fibrosis. Pediatrics 1968;41:7-17.

Kaplan E, Shwachmann H, Perlmutter AD, Rule A, Khaw K-T, Holsclaw DS. Reproductive failure in males with cystic fibrosis. $N$ Engl I Med 1968;279:65-9.

3 Landing BH, Wells TR, Wang C-I. Abnormality of the epididymis and vas deferens in cystic fibrosis. Arch Pathol 1969;88:569-80.

4 Dumar V, Gervais R, Rigot J-M, Lafitte J, Manouvriers S, Biserte J, et al. Abnormal distribution of CF $\triangle F 508$ allele in azoospermic men with congenital aplasia of epididymis and vas deferens. Lancet 1990;336:512.

5 Anguiano A, Oates RD, Amos JA, Dean M, Gerrard B, Stewart C, et al. Congenital bilateral absence of the vas deferens: a primarily genital form of cystic fibrosis. JAMA 1992;267:1794-7.

6 Silber SJ, Ord T, Balmaceda J, Patrizzio P, Asch RH. Congenital absence of the vas deferens: the fertilizing capacity of human epididymal sperm. N Engl f Med 1990;323:1788-92.

7 Oates RD, Honig S, Berger MJ, Harris D. Microscopic epididymal sperm aspiration (MESA) a new option for the treatment of obstructive azoospermia associated with cystic fibrosis. f Assist Reprod Genet 1992;9:36-40.

8 Hames A, Beesley J, Nelson R. Cystic fibrosis: what do patients know and what else would they like to know? Respir Med 1991;85:389-92.
9 Nolan T, Desmond K, Herlich R, Hardy S. Knowledge of cystic fibrosis in patients and their parents. Pediatrics 1986;77:229-35.

10 Kopito LE, Kosasky HJ, Schwachman H. Water and electrolytes in cervical mucus from patients with cystic fibrosis. Fertil Steril 1973;24:512-6.

11 Sawyer SM, Phelan PD, Bowes B. Vulvovaginal candidiasis in young women with cystic fibrosis. $B M F$ 1994;308:1690

12 Kelly A. The primary care provider's role in caring for young people with chronic illness. f Adolesc Health 1995;17:32-6.

13 Sawyer SM, Phelan PD, Bowes G. Reproductive health in young women with cystic fibrosis: knowledge, behaviour and attitudes. F Adolesc Health 1995;17:46-50.

14 Wright SM, Gabb RG, Ryan MM. Reproductive health: knowledge, attitudes and needs of adolescents. Med $\mathcal{F}$ Aust 1991;155:325-8.

15 Neinstein LS, Katz B. Contraceptive use in the chronically ill adolescent female: part 1. I Adolesc Health Care 1986;7:123-33.

16 Mahlstedt PP. The psychological component of infertility. Fertil Steril 1985;43:335-46.

17 Sawyer SM, Tully MA, Dovey M, Colin AA. Reproductive health in males with cystic fibrosis: a questionnaire study of the practice and attitudes of CF physicians. Ped Pulmonol 1995;Suppl $12: 289$

\title{
Dyslexia: a hundred years on
}

\author{
$A$ verbal not a visual disorder, which responds to early intervention
}

The first case of developmental dyslexia was reported by PringleMorgan in the BMF on 7 November $1896 .{ }^{1}$ Pringle-Morgan, a general practitioner, and Hinshelwood, an ophthalmologist also writing at the turn of the century, ${ }^{2}$ speculated that such difficulties with reading and writing were due to "congenital word blindness," and for many years the dominant view was that dyslexia was caused by visual processing deficiencies. There is still continuing interest in the role of visual factors in the aetiology of dyslexia, especially in low level impairments of the visual system. ${ }^{34}$ However, most research suggests that these are not its cause. The most widely accepted view today is that dyslexia is a verbal deficit ${ }^{5}$ and can be considered part of the continuum of language disorders. Indeed, converging evidence supports a specific theory, that dyslexic readers have phonological (speech) processing deficits.

Dyslexia tends to runs in families, and the relatives of dyslexic readers often have other language problems. Dyslexia is more common in boys than girls, and there is strong evidence that it is heritable; the probability of a boy becoming dyslexic if his father is dyslexic can be as high as $50 \%$; it is somewhat lower for a girl. Results of large scale twin studies suggest that sensitivity to speech sounds (as measured by tests of rhyming skill) shares genetic variance with phonological reading skills. ${ }^{6}$ Gene markers on chromosomes 1 and 15 have been identified in dyslexic families, and linkage on chromosome 6 in the region of the human leucocyte complex may explain an often reported association between dyslexia and autoimmune disease. ${ }^{7}$ There have also been advances in the neurobiology of dyslexia. Evidence on brain abnormalities has implicated the perisylvanian regions, and postmortem studies have revealed unusual symmetry of the plenum temperale with cortical dysplasia and scarring. ${ }^{8}$

Dyslexia is a developmental disorder that affects people of all ages, but its symptom profile changes with age. Studies of children at genetic risk of dyslexia have reported difficulties in speech production and grammatical expression at 30 months, followed by slower vocabulary acquisition during the preschool years, culminating in deficits in phonological awareness and alphabet knowledge in young schoolchildren. ${ }^{9}$ Parental reports of delayed speech and language among children with reading difficulties have been common in epidemiological studies.

The most comprehensive picture of dyslexia available is in children of school age. ${ }^{10}$ Although in most cases speech perceptual abilities are intact, dyslexic children have difficulty in reflecting on the sound structure of spoken words. Such phonological problems make it difficult to learn how the letters and sounds of printed words are related. Most dyslexic children have difficulty using a phonic approach to reading, and their spelling often fails to represent the sound structure of target words. Although dyslexic children overcome many of their difficulties, in adulthood they experience subtle problems with phonological awareness and reading and writing skills. Functional brain imaging is beginning to elucidate why this is so; it has been shown that, when dyslexic adults perform rhyme judgment and verbal short term memory tasks, they activate only a subset of the brain regions usually involved. Plausibly, their phonological difficulties may be due to weak connectivity between anterior and posterior language areas of the left hemisphere. ${ }^{11}$

Knowledge of the predictors of reading achievement and of dyslexia has led to innovations in methods of intervention. A pioneering study in Oxford showed that children who performed poorly on a phonological processing task before they went to school benefited significantly from a training programme in sound categorisation using rhyme and alliteration activities, particularly when it was combined with teaching of letter sounds. ${ }^{12}$ Subsequently, it has been shown that training in phonological awareness combined with a structured reading intervention is an effective form of treatment for poor readers and produces greater gains than training in either reading or phonological awareness alone. ${ }^{13}$

Although the term dyslexia remains debated, there is good evidence that unexpected reading problems in children are caused by language deficiencies within the phonological domain. Children with reading difficulties report a variety of psychosomatic problems: complaints of headaches and difficulties in seeing are common. A detailed case and family history may uncover dyslexic difficulties, and the routine assessment of preschool children can usefully incorporate a test of knowledge of nursery rhymes and letters. ${ }^{14}$ Clinical experience shows that, with regard to dyslexia, it is a fallacy to "wait and see how the child develops." A delay at the start of learning to read can quickly develop into a considerable reading disorder if unattended.

\section{MARGARET I SNOWLING} Professor

Department of Psychology,

University of York,

York YO1 5DD

Pringle-Morgan W. A case of congenital word blindness. $B M 7$ 1896; ii: 178

2 Hinshelwood J. Congenital word blindness. London: HK Lewis, 1917.

3 Eden GF, VanMeter JW, Rumsey JM, Maisog JM, Woods RP, Zeffiro TA. Abnormal processing of visual motion in dyslexia revealed by functional brain imaging. Nature 1996;382:66-9.

4 Lovegrove WJ, Williams MC. Visual temporal processing deficits in specific reading disability. In: Willows DM, Kruk RS, Corcos $\mathrm{E}$, eds. Visual processes in reading and reading disabilities. Hillsdale, NJ: Lawrence Erlbaum Associates, 1993: 311-30.

5 Vellutino FR. Dyslexia: theory and research. Cambridge, MA: MIT Press, 1979.

6 Olson RK, Wise B, Conners F, Rack J, Fulker D. Specific deficits in reading and component language skills: genetic and environmental influences. Fournal of Learning Disabilities 1989;22:339-48

7 Cardon LR, Smith SD, Fulker DW, Kimberling WJ, Pennington BF, DeFries JC. Quantitative trait locus for reading disability on chromosome 6. Science 1994;266:276-9.

8 Galaburda AM. Neurology of developmental dyslexia. Curr Opin Neurobiol 1993;5:71-6. 


\title{
The doctrine of early intervention
}

\author{
When assessing interventions, context is more important than doctrine
}

The principle of early intervention in a disease process is intuitively appealing. Clearly, where early intervention is synonymous with primary prevention, the principle is sound. You need only to look at the fall in recorded cases of poliomyelitis or meningitis caused by Haemophilus influenzae type B after the introduction of their respective vaccines for confirmation of the value of appropriate early intervention. ${ }^{1}$ But when early intervention means secondary prevention the issue is less clear. We know now that a combination of exercise, diet, and intensive treatment with insulin can delay the start of microvascular complications in patients with insulin dependent diabetes mellitus. ${ }^{2}$ On the other hand, considerable debate surrounds the treatment and surveillance of patients diagnosed with ductal carcinoma of the breast, ${ }^{3}$ prostate cancer, ${ }^{4}$ or malignant melanoma. $^{5}$

A recent editorial in the New England fournal of Medicine appraising a paper by Weinberger et al presented what its author called the "heretical view" that the doctrine of early intervention might be wrong. ${ }^{7}$ The aim of Weinberger et al's multicentre study, based on data from Veterans' Affairs centres across the United States, was to assess whether early intervention in patients who had recently been discharged from hospital with diabetes, chronic obstructive pulmonary disease, or congestive cardiac failure could prevent their readmission to hospital. The intervention, which comprised close follow up by a nurse and primary care physician at the local clinic and in the patient's home, produced the opposite effect: patients who received the early intervention had higher monthly readmission rates and spent longer in hospital than patients in the control group receiving usual care. The author of the editorial observed that "closer scrutiny of the patients simply led to more medical care and perhaps to harm"-although there was no evidence that the patients were harmed by the care they received. Is the conclusion of the editorial-that the doctrine of early intervention may be wrong-correct?

Weinberger et al's study was really an exercise in tertiary prevention, and their use of the term "early intervention" in this context is misleading. The patients in the study were in the end stages of their diseases - half of those with congestive cardiac failure were classified as grade III or IV, a third of the patients with diabetes had end organ damage, and a quarter of those with chronic obstructive pulmonary disease required domiciliary oxygen. Two thirds of the intervention group were classified at the beginning of the study as at medium or high risk of readmission, and nearly $8 \%$ of the whole study population died during the six month study. Accordingly, the failure of the intervention to prevent readmission may reflect more the severity of the study population's illness than the inadequacy of the strategy.

The extensive burden of illness in the patients in this study, coupled with the large amount of direct medical care and proactive telephone advice they received, created ample opportunities for the initiation of what have been described as clinical cascades. ${ }^{8}$ Here, a single seemingly innocuous clinical characteristic, like a patient's or even health professional's anxiety, initiates an unstoppable series of events resulting in more and more medical care being offered. Even so, the analysis offered by the authors of this study says nothing about the appropriateness of the interventions and admissions, which may have been entirely justifiable.

The exclusion criteria used in this study pose some questions about its generalisability. Firstly, the Veterans' Affairs system offers medical care to a predominantly low income population, including those who are homeless and chronically mentally ill. ${ }^{9}$ Less than half of those initially eligible to take part in the study actually participated, roughly $10 \%$ of the screened population. Nearly a third of those who were eligible to take part declined to do so because they did not wish to be assigned to a new doctor whom they did not know. This makes the study less relevant to doctors in Britain and other countries where patients are discharged back into the care of their own general practitioner. ${ }^{10}$

Should doctors support the doctrine of early intervention, or any other doctrine for that matter? A doctrine is defined as "the principles or dogmas of a scientific school."11 when an intervention is being assessed, is it not more important to assess whether the activity is appropriate and effective? Any intervention should be based on evidence that is relevant, robust, and reliable; it should meet the patient's needs, and be tailored to the context in which those needs arise. Weinberger et als paper shows that this vulnerable patient group consumed a large amount of medical resources: what it does not show is whether these resources were justified and effectively consumed.

KG SWEENEY General practitioner DJ PEREIRA GRAY General practitioner PH ĖVANS General practitioner RJF STEELE

St Leonard's Medical Practice, General practitioner

34 Denmark Road,

Exeter EX1 1SF

1 Department of Health and Welsh Office. Immunisation against infectious diseases. London: HMSO, 1992

2 Diabetes Control and Complications Trial Research Group. The effect of intensive treatment of diabetes on the development and progression of long term complications in insulin dependent diabetes mellitus. $N$ Engl $\mathcal{F}$ Med 1993;329:977-86.

3 Del Turci MR, Pali D, Cardidi A, Ciatto S, Pacini P, Distante V for the National Research Project on Breast Cancer Follow-up. Intensive diagnostic follow-up after treatment of primary breast cancer: a randomised trial. $¥ A M A$ 1994;271:1587-92.

4 Krahn MD, Mahoney J, Eckman MH, Trachtenberg MD, Paulker SG, Detsky AS. Screening for prostate cancer. YAMA 1994;272:773-80.

5 Weiss M, Loprinzi CL, Creagan ET, Dalton RJ, Novotny P, O'Fallon JR. Utility of follow-up for detecting recurrent disease in patients with malignant melanomas. अAMA 1995;271:1703-5. 6 Weinberger M, Oddone EZ, Henderson WG for the Veterans Affairs Co-operative Study Group on Primary Care and Hospital Readmission. Does increased access to primary care reduce hospital admissions? N Engl I Med 1996;334:1441-7.

7 Welch HG. Questions about the value of early intervention. N Engl $f$ Med 1996,334:1472-3.

8 Mold JW, Stein HF. The cascade effect in the clinical care of patients. N Engl f Med 1986; 314:512-4.

9 Fisher ES, Welch HG. The future of the department of Veterans Affairs health care system. fAMA 1995;273:651-5.

10 Pereira Gray DJ, Steele RJF, Sweeney KG, Evans PH. Generalists in medicine. BMf 1994; 308:486-7.

11 Kirkpatrick B, ed. Cassell concise English dictionary. London: Cassell, 1994. 